\title{
José Luis Blas Arroyo / Juan González-Martínez Escritura, oralidad y variación: nuevos datos sobre la alternancia allí/allá a la luz de un corpus epistolar del siglo XVI
}

https://doi.org/10.1515/zrp-2019-0058

\begin{abstract}
This corpus-based research uses a set of 895 private letters written by almost seven hundred different individuals to analyse the variation between the Spanish adverbs allí and allá in the sixteenth century. The figures found in this study are quite different from those of previous research. Whereas some researchers have highlighted the common prevalence of alli, our data reveal a greater prominence of the form allá in this period, which was found to be more frequent in every single context taken into account in the analysis. This study considers the differences in the textual framework as a probable cause of these important quantitative divergences. At the same time, the paper uses tools from historical sociolinguistics to examine the incidence of the variable context in the selection of the adverbial forms. Our results confirm the influence of some constraints previously highlighted in the literature, but contradict others. Moreover, even the former need to be reinterpreted in variationist terms, and never as an expression of differences in the linguistic system.
\end{abstract}

Keywords: historical sociolinguistics, language variation and change, demonstrative adverbs, allí / allá variation, epistolary corpus, mixed-effects logistic regression, Spanish

Palabras clave: sociolingüística histórica, variación y cambio lingüístico, adverbios demostrativos, alternancia allí / allá, corpus epistolar, regresión logística de efectos mixtos, español

Promovido por: El presente artículo se inscribe en el proyecto de investigación «Dimensiones estructurales, sociales e idiolectales del cambio lingüístico: nuevas aportaciones desde la sociolingüística histórica al estudio del español», financiado por el Ministerio de Economía y Competitividad (Ref. FFI2017-86194-P) y la Universitat Jaume I (UJI B2017 01).

Dirección de correspondencia: Prof. Dr. José Luis Blas Arroyo, Universitat Jaume I, Departamento de Filología y Culturas, Avenida Sos Baynat s/n, E-12071 Castellón, E-Mail: blas@fil.uji.es Dr. Juan González-Martínez, Universitat de Girona, Departament de Pedagogia, Plaça de Sant Domènech, 9, E-17004 Girona, E-Mail: juan.gonzalez@udg.edu 


\section{Introducción}

En los últimos años, se ha llamado la atención acerca del modo en que las complejas diferencias entre la oralidad y la escritura $-\mathrm{y}$ en el interior de estas, entre diferentes géneros y tradiciones discursivas- pueden condicionar la variabilidad inherente a la lengua en numerosas áreas de la gramática (cf. Biber 1995, Cano 2003, Koch/Oesterreicher 2007, López Serena 2007, Kabatek 2008, Company 2012, Company/Espinosa 2014, entre otros). En el curso de un proyecto de investigación en sociolingüística histórica para el estudio diacrónico del español, nosotros mismos hemos tenido ocasión de comprobar cómo el diagnóstico acerca de la evolución de ciertos fenómenos de variación fluctuaba, en ocasiones considerablemente, en función del marco textual, ya se tratara de textos más cercanos al polo de la inmediatez comunicativa, como los epistolarios privados, ya fueran de carácter más formal y escriturario (literarios, jurídicos, administrativos, etc.). Así, en otro lugar hemos sugerido cómo algunas diferencias en torno a la distribución de las variantes prepositiva y no prepositiva de las perífrasis modales con el verbo deber (Blas Arroyo/González-Martínez 2014) o la alternancia entre haber de y tener que + infinitivo podrían explicarse conforme a este principio. En relación con este último hecho de variación, por ejemplo, un análisis sistemático del contexto variable basado en textos epistolares del siglo XIX nos permitió comprobar cómo la perífrasis tener que + infinitivo superaba ya a su eterna rival en la segunda mitad de esta centuria, contrariamente a lo supuesto a raíz de recuentos previos basados en tradiciones discursivas más formales (Blas Arroyo/Porcar/Vellón 2013). Asimismo, la elisión del nexo subordinante en subordinadas dependientes de verbos doxásticos durante los Siglos de Oro (creo (que) no lo hará), debió de ser mucho más frecuente de lo que se había supuesto, a juzgar por la extraordinaria recurrencia que muestra en textos epistolares y autobiográficos de la época (Blas Arroyo/Porcar 2016).

En el presente estudio queremos poner de nuevo a prueba esta hipótesis, analizando otro hecho de variación que encontramos a lo largo de toda la historia del español: la alternancia entre los adverbios demostrativos allí/allá. Representantes de los dos subsistemas en que se organizan estos adverbios, las formas en -á (a la que pertenecen también acá y la arcaica acullá) y las formas en -í (en compañía de aquí y ahí, además del medieval y), diversos lingüistas han postulado diferencias entre ambos en el sistema lingüístico. A este respecto, se ha dicho, por ejemplo, que la principal divergencia entre los dos bloques de adverbios estaría en la manera de conceptualizar el eje espacial (y, por extensión metafórica, también temporal): ya de manera dinámica, en unas coordenadas espaciales (y temporales) imprecisas (con los adverbios en -á), ya de forma estática, en coordenadas mucho más puntuales y precisas (en el caso de las formas en -î). Al mismo 
tiempo, se ha propuesto que estos adverbios demostrativos exhiben un grado de distancia diferente con respecto al hablante, interpretada esta no tanto en términos reales cuanto psicológicos. De ser ello cierto, allá establecería un mayor nivel de alejamiento que allí, a partir de la idea de indeterminación asociada al primero, que, por el contrario, no existiría en el segundo (cf. Seco 1967; DCECH; Terrado 1990a; Villegas 1990).

Con todo, incluso quienes abogan por la diferencia entre estos adverbios en el sistema lingüístico coinciden en que, en el uso real, las cosas pueden ser bien diferentes. Por un lado, nos encontramos con el hecho constatable de que, en el discurso, los hablantes se sirven a menudo de formas distintas para cubrir una misma necesidad comunicativa o, lo que es lo mismo, para 'referirse a lo mismo'. Esta «comparabilidad» (Lavandera 1984, 45) o neutralización funcional está en la base de la génesis misma del cambio lingüístico, ya que sin la existencia de tales «opciones» alternativas, no habría necesidad de evolución alguna (Poplack/Malvar 2007, 134). Los ejemplos de (1) y (2), a continuación, extraídos del corpus que sirve como base a esta investigación, muestran cómo las formas allí y allá se utilizan alternativamente en un mismo entorno semántico. Obsérvese, en efecto, cómo la forma adverbial está asociada en los dos casos a una referencia espacial precisa, la ciudad de Sevilla, a la que aluden dos emigrantes en Indias en sendas cartas a sus allegados en España:

(1) ... se vien[e?] fasta sevilla en vn carro o dos y alli se aliñan de todo p[ar]a pasar adelante (Cartas de particulares en Indias del siglo XVI, 1587).

(2) ... aca nos dan tan malas nuevas que alla en sevilla la toman i toda para el rey (Cartas de particulares en Indias del siglo XVI, 1577).

La constatación de esta alternancia posible en muchos contextos, reconocida ya desde hace décadas (RAE 1931, 122), ha llevado a su interpretación reciente como una potencial variable lingüística y, por tanto, como objeto de estudio de la sociolingüística. Mediante las herramientas teóricas y metodológicas de esta disciplina, en la actualidad disponemos de diversos estudios en los que se han analizado los factores lingüísticos y extralingüísticos que condicionan esta variación en diversas comunidades de habla del mundo hispánico (cf. Carbonero Cano 1979; Sedano 1996, 2000; Gallucci 2007). Las cosas son, sin embargo, distintas en la diacronía. Hasta donde llega nuestro conocimiento, no disponemos de estudios que hayan examinado exhaustivamente la influencia global de ese contexto variable en la selección de los adverbios allí y allá en periodos previos de la historia del español. Y no solo en términos frecuenciales, sino también, y sobre todo, en el modo en que han evolucionado la gramática interna y el componente socio-estilístico a lo largo del eje diacrónico. Así las cosas, y como primer hito en este proyecto de estudio de los patrones de variación y potencial cambio lingüístico entre 
las dos formas alternantes a lo largo de la historia, en lo que sigue ofrecemos los principales resultados de un estudio variacionista a partir de un corpus compuesto por cartas privadas del siglo XVI, escritas por más de seiscientos autores diferentes a uno y otro lado del Atlántico.

La elección de este corpus obedece al convencimiento de que sus textos nos aproximan como pocos al habla vernácula de tiempos pretéritos. Además, ello quizá explique las diferencias de calado que encontramos con otros recuentos efectuados recientemente y con la supuesta incidencia de ciertos factores que se repiten en la bibliografía. Así, en una minuciosa aproximación diacrónica reciente a los pronombres demostrativos, Company/Espinosa $(2014,187)$ advierten que, al margen de las oposiciones sistémicas a las que nos referíamos más arriba, la lengua española «se ha decantado siempre por formas en -i para expresar el espacio y el tiempo, sea en reposo sea en movimiento» (ib.). En concreto, y por lo que a las formas que aquí nos interesan se refiere, los recuentos efectuados en varios siglos muestran un destacado predominio del adverbio allí a lo largo de toda la historia del español, no solo en relación con todos los demás adverbios, sino también con la forma alternante para la expresión de la lejanía, allá. De este modo, en el corpus del siglo XVI manejado por estas autoras, ${ }^{1}$ el adverbio allí supone el $48 \%$ de todos los adverbios demostrativos encontrados, a considerable distancia de allá, que apenas representa el 9\%.

Como veremos, nuestros datos son considerablemente distintos, con un predominio claro de la forma allá en el conjunto de la centuria, aunque con una tendencia a la ampliación de usos de su rival, especialmente en las últimas décadas del siglo. Con todo, las diferencias no se limitan al mero contraste frecuencial. Como tendremos ocasión de comprobar, junto a la presencia de factores cuya influencia se ha intuido - o confirmado- en otras sincronías, otros no se comportan en este periodo de acuerdo con lo postulado en la bibliografía. Además, la interpretación de estos factores debe rehacerse de acuerdo con parámetros diferentes a los utilizados habitualmente.

A partir de estas primeras coordenadas, este artículo se estructura de la siguiente manera. En el apartado §2, presentamos los antecedentes históricos de la variable y examinamos con detalle los diferentes entornos analizados, pasando revista a lo advertido previamente por la tradición lingüística, y ejemplificando,

1 Este se halla integrado por una novela picaresca, el Lazarillo de Tormes, la Historia verdadera de la conquista de la Nueva España de Bernal Díaz del Castillo y los Documentos lingüísticos de la Nueva España, editados por la propia Company (1994). En este sentido, el corpus recoge una muestra de escritores más reducida que la utilizada en nuestro corpus. Por otro lado, no es descartable que las veleidades estilísticas de algunos de sus autores hayan podido introducir algún sesgo en los resultados. 
con fragmentos representativos del corpus, cada uno de los factores considerados. A continuación, daremos cuenta de las principales magnitudes y caracteres del corpus epistolar seleccionado, así como de las herramientas metodológicas empleadas en el estudio empírico (§3). El cuerpo principal del trabajo corresponde al apartado §4, donde llevamos a cabo la presentación y el análisis de los resultados cuantitativos. Finalmente, en §5 sintetizaremos las principales conclusiones e implicaciones teóricas del estudio.

\section{La variable lingüística: historia y codificación}

Comúnmente, se acepta que la forma allí procede de *ad illic (DCECH s.v. alli; Sánchez Lancis 1990) y, en su primeras manifestaciones escritas (ya a comienzos del siglo XII), aparece con diversos valores locativos, como la dirección, la ubicación, el origen y el trayecto. Más adelante, a partir del siglo XV, encontramos también los primeros valores temporales, como consecuencia de una traslación metafórica desde las coordenadas espaciales (Company/Espinosa 2014, 161). En nuestro corpus, sin embargo, apenas hemos encontrado usos temporales de este tipo, como los de (3):

(3) en hos pedaje y os aviara fasta nonbre de dios y de alli en dos dias sere yo con vos señora herna y sera (Cartas de particulares en Indias del siglo XVI, 1580).

Por su parte, allá deriva de *ad illac, combinación en la que el segundo elemento señalaba tránsito en latín ('por allá'). Aparece ya en el Cantar de Mio Çid, y, como hemos visto, en opinión de varios autores tiene un significado diferente al de allí. Por ejemplo, a juicio de Corominas (DCECH s.v. allâ) «[allá] se ha diferenciado siempre de allí por referirse a un lugar más amplio [...] o localizado más vagamente. También se nota que la relación de movimiento a o hacia un lugar se expresa normalmente con allá y raras veces con allì. Sin embargo, a juicio de Company/ Espinosa (2014, 162), este adverbio perdió ese significado primitivo para adoptar otros, también comunes a allí, como la ubicación, la dirección y el origen.

En lo que sigue, desarrollamos más detalladamente estas y otras ideas relacionadas con el condicionamiento variable de los adverbios demostrativos que encontramos en la bibliografía lingüística. A partir de estas, y de algunas otras intuiciones personales, codificamos la variable para su estudio cuantitativo posterior. Una sinopsis de esos factores aparece más adelante en la tabla 1. 


\subsection{Delimitación}

Como hemos apuntado más arriba, en la tradición gramatical existe una idea recurrente según la cual los adverbios en á, como allá, dan cuenta de coordenadas espacio-temporales amplias, imprecisas o mal delimitadas, por lo que aceptan de mejor grado incrementos como la cuantificación (Company/Espinosa 2014, 187). Para explicar este sentido se han propuesto diversas hipótesis, entre ellas la de que el significado originario, de tránsito, de los adverbios latinos ('lugar por donde') podría haberse extendido más adelante para incluir espacios amplios y mal acotados (Sedano 1996, 44). ${ }^{2}$ Por el contrario, los adverbios de la serie en -í definen espacios y tiempos de manera mucho más precisa, de tal manera que se pueden conceptualizar como puntos en el mencionado eje, y no como zonas genéricas (Cuervo 1953, 6; Seco 1967, 29; Carbonero 1979, 88; RAE 1992, 11 y 85; Sedano 2000, 927).

En todo caso, se ha advertido también que esa delimitación espacial puede ser antes una percepción del hablante que una distancia real (Terrado 1990b; Pérez Saldanya/Rigau 2011), lo que no ayuda precisamente a la evaluación empírica del factor. De ahí que, para su configuración en nuestro corpus, hayamos acudido a las precisiones en el contexto inmediato. De este modo, si en ese contexto, el emisor hace explícita la referencia a ese espacio lejano al punto o momento del habla, nos hallaremos ante entornos precisos, como los de (4) y (5). Por el contrario, si no es así, y las referencias espaciales o temporales no se concretan, los ejemplos correspondientes serán codificados como imprecisos, como en (6) y (7). Dadas las características estructurales de las cartas, en muchos de estos casos, el remitente apunta a espacios ciertamente vagos e indeterminados, aunque se intuye que cercanos al ámbito donde se ubica el destinatario y donde en otro tiempo estuvo también el remitente. Así se aprecia, por ejemplo, en (7), donde Francisco Rodríguez Santos, tesorero de la catedral de México, escribe a Hernán Pinto, vecino de Villabrágima (Valladolid) para ponerle al tanto de diversas cuestiones. Entre estas, dejar una cierta cantidad de dinero a un familiar, que se obtendrán de las posesiones que «allá tuviere» el remitente:

2 Asimismo, esta autora alude al simbolismo de las vocales como una posible razón cognitiva en la diferente delimitación espacial de allí y allá. A este respecto, recuerda las tesis de autores como Jakobson (1960) y Sacks (1987), quienes advertían que, aun inconscientemente, la vocal $i$ «suele asociarse a espacios pequeños, en tanto que la vocal $a$ se asocia a áreas más extensas. La relación de la vocal $a$ con lugares extensos podría incluir también la referencia a espacios poco circunscritos» (Sedano 1996, 44). 
(4) ... la de n[uest]ra madre los partiréys para Sebilla y alli acudiréys a Estevan López, el mercader... (Die private Korrespondenz spanischer Emigranten aus Amerika, 1587).

(5) ... va para otro su fator de sevilla el qual bereys alla y envio dineros quinientos $\mathrm{p}^{\mathrm{o}} \mathrm{s}$ de oro (Cartas de particulares en Indias del siglo XVI, 1556).

(6) Y que luego, en dándome las cartas las abrí allí delante de ellos y vieron como decían que era muerta mi mujer y una hermana mía (El hilo que une, 1572).

(7) ... si fuere menester para el despacho algunos dineros tómense, de lo que yo allá tubiere o de lo que primero me perteneciere (Desde la otra orilla, 1570).

\subsection{Sentido}

Junto al tipo de delimitación espacial y su potencial incidencia en la selección de allí y allá, se ha propuesto también que este último adverbio, al igual que otros de la misma serie (acá), denotan circunstancias locativas dinámicas, mientras que el primero está asociado a sentidos estáticos (Bello 1972, 118s.; Carbonero Cano 1979, 75; RAE/ASALE 2009, §17.8fg). Para algunos autores, el hecho de que en latín el sistema de casos permitiera establecer una distinción entre la direccionalidad y la simple ubicación podría explicar que tal dicotomía se haya perpetuado en español mediante las dos series formales de adverbios.

En nuestro estudio, este factor semántico se ha conceptualizado a través del sentido de la locación, distinguiendo así entre estados, como en (8) y (9), y diferentes tipos de movimientos: desde un origen, (10) y (11), hacia un destino, (12) y (13), y aquellos, finalmente, que implican el tránsito por un lugar, como los de (14) y (15):

(8) ... lo que biere que conbiene y por la rresidencia que alla está, que la e hecho entenderá vuestra merçed... (Desde la otra orilla, 1559).

(9) ...las cartas des de la veracruz para q yo sepan qstan alli para q les enbie recaudo para subir de la veracruz (Cartas de particulares en Indias del siglo XVI, 1577).

(10) ... yo si guardo, mas es menester que me escriba desde allá, mas paréceme que anda el juego como acá (El hilo que une, 1597).

(11) ... no os acordasades de my pues a . tantos ase q de alla sali y a my hijo dexe asi q quyero q entendais (Cartas de particulares en Indias del siglo XVI, 1565).

(12) ... y se fue se conmigo y me aconpañase hasta alla porque la costa que hiciere en el uiax pagare (Cartas de particulares en Indias del siglo XVI, 1573).

(13) ... por la qual vera vra merçed el suceso de la uenida hasta alli (Cartas de particulares en Indias del siglo XVI, 1583).

(14) ... yo queria nos abaxaxemos por alla hazia lima do esta el señor visorrey (Cartas de particulares en Indias del siglo XVI, 1576).

(15) ...me embio a dezir q entiende yr en españa quando pase por alli esta flota . yo le escrivo muy largo y le encomiendo sus cosas de vm (Cartas de particulares en Indias del siglo XVI, 1573). 


\subsection{Presencia/ausencia de preposición}

Algunos de los usos direccionales descritos en el apartado anterior están íntimamente asociados a determinadas preposiciones, con las que los adverbios demostrativos guardan una estrecha relación desde antiguo. Así, ocurre, por ejemplo, con las preposiciones de (170), ${ }^{3}$ por (126), desde (21), para (15) y hasta (4). Con todo, algunos de estos sentidos pueden aparecer también sin el auxilio de una preposición, y de hecho así ocurre más frecuentemente en los textos. De este modo lo advierten, por ejemplo, Company/Espinosa $(2014,202)$ en diversos cortes de la historia del español, con cifras generales que alcanzan el $77 \%,{ }^{4}$ similares a las que encontramos también nosotros en el corpus epistolar del siglo XVI $(75 \%$; $n=894)$. Company/Espinosa (2014, 201ss.) señalan también que la diferencia entre usos prepositivos y no prepositivos es sensible a las series en -í y en -áa, especialmente en las primeras etapas de la historia del español. Así, en el siglo XIII, la presencia del elemento prepositivo se produce en un $20 \%$ de los adverbios en $i$, frente a tan solo un $2 \%$ en los miembros de la otra serie. Estas diferencias se atenúan considerablemente en el siglo XVI, aunque mantienen la misma dirección explicativa ( $25 \%$ vs. $19 \%)$.

Nosotros también hemos querido evaluar la potencial incidencia de este factor en el corpus de referencia en este estudio, codificando todas las ocurrencias de allí y allá de acuerdo con este criterio. Así, frente a los ejemplos anteriores de (10) a (15), que representan entornos prepositivos, los de (16) y (17) reproducen usos no prepositivos:

(16) ....[en] la beracru sea despachado porqs tierra [en]ferma y no se detenga alli si fuere posible vna ora (Cartas de particulares en Indias del siglo XVI, 1594).

(17) ...y cinquenta pesos de plata ensayada que baldrán allá en Sevilla trecientos ducados menos las costas q (Die private Korrespondenz spanischer Emigranten aus Amerika, 1590).

\subsection{Modo de acción verbal}

La variación entre allí y allá se ha puesto también en relación con la clase semántica de los predicados en que participan los adverbios demostrativos. Así, Company/Espinosa $(2014,211)$ señalan que los adverbios de «la serie en $i$ aparecen

3 Entre paréntesis figura el número de ocurrencias en el corpus.

4 Con todo, estas autoras señalan un incremento de los empleos preposicionales a medida que pasa el tiempo. 
siempre en mayor número de ocasiones con verbos de estado y se afianza diacrónicamente con esta clase de verbos: siglo XIII 31\%; XVI 31\%; XIX 41\%». Por el contrario, hay una tendencia a ver los adverbios en $a$ asociados a verbos de movimiento, aunque se reconoce que «su porcentaje disminuye considerablemente en cada corte cronológico: [XIII] 74\%; [XVI] 36\%; [XX] 31\%».

Para evaluar esta alianza entre el modo de acción de los verbos y la alternancia adverbial en el siglo XVI, distinguimos entre contextos adverbiales con verbos estativos, de movimiento, acción, y lengua. Cada uno de ellos aparece ejemplificado a continuación en los siguientes fragmentos:

(18) ... y digo p[ar]a que podra . ser qdo esta llegue estar alla y podra vm sabr del la cabsa de lo dho (Cartas de particulares en Indias del siglo XVI, 1557).

(19) con vnos caracoles grandes y palmitos nos estubimos alli sie[te?] dias a los quales salimos p[ar]a venir... (Cartas de particulares en Indias del siglo XVI, 1595).

(20) ...que tiene sy dios fuere servido y esta nao llegare alla con esta ca[rta] (Cartas de particulares en Indias del siglo XVI, 1559).

(21) y se binieron y el p[ero?] hernandez se huyo de alli con poca gente ... (Cartas de particulares en Indias del siglo XVI, 1554).

(22) ... pescado [en] cantidad vino de dos o tres maneras de frutas que alla fazen y esto es [en] las yslas donde agora estan poblados (Cartas de particulares en Indias del siglo XVI, 1574).

(23) ... dios sabe lo que lo senti, en fin hiçimos allí matalotaje de nueuo y partimos de este puerto ... (Cartas de particulares en Indias del siglo XVI, 1587).

(24) ... escribame con el muy largo de todo lo de por allá que sera para my mucho contento ) saberlo (Cartas de particulares en Indias del siglo XVI, 1567).

(25) la cual va a v.md., que por escribirla allí la he hecho. No lo soy en ésta más (Cartas de particulares en Indias del siglo XVI, 1573).

\subsection{Función}

Sintácticamente, los adverbios de lugar del corpus, pueden ser complementos de un verbo -opción abrumadora (94\%), como en (26)-, pero también de sustantivos, pronombres e incluso otros adverbios, esta vez mediante el enlace de. En todo caso, dadas las limitaciones de estos contextos en la muestra, para el análisis de regresión se agrupan en un solo bloque (Otros). Sin embargo, no documentamos ningún ejemplo de usos absolutos, más propios de la oralidad, como en la respuesta a una pregunta: ¿Dónde estabas? Allí.

(26) ...suplico a vuestra merçed, si tubiere noticia que está allá, trate de que se me mande cunplir la merçed ... (Desde la otra orilla, 1559). 
(27) ... uengan . a vn pueblo . que se diçe quenca que de ayi yo terne aviso y les enbiare todo aviamiento ... (Cartas de particulares en Indias del siglo XVI, 1560).

(28) ...para remediar a esas hemanas . que no el de alla sin of 0 ni açienda . y plugiera a dios . que alguna de mis sobrinas . estuvieran en hedad... (Cartas de particulares en Indias del siglo XVI, 1584).

(29) ... q llaman frco peres verdugo de la para o cerca de alli segun me dizen po[r]q de q se caso no e tenido carta suya (Cartas de particulares en Indias del siglo XVI, 1585).

\subsection{Combinatoria}

Normalmente, los adverbios se construyen en solitario, sin expansión sintáctica alguna. En nuestro corpus, este contexto, ejemplificado en (30) y (31), alcanza cifras cercanas a lo categórico (96\%), superando las ya de por sí muy elevadas (87\%) que encuentran Company/Espinosa (2014) en diversos cortes cronológicos del español. No obstante, el hecho de que el primero aventaje en casi diez puntos porcentuales al segundo quizá sea un reflejo del carácter más cercano al polo de la inmediatez comunicativa de los textos epistolares, menos propicios a los incrementos sintácticos en una categoría cuya combinatoria sintagmática es, como vemos, muy débil. Sea como sea, lo cierto es que en las cartas del siglo XVI, tan solo encontramos 46 ejemplos con algún tipo de complementación, ya sea mediante el uso de sintagmas preposicionales, como en (32) y (33), ya de sintagmas adverbiales $\mathrm{u}$ oraciones de relativo especificativas: ${ }^{5}$

(30) ... del otro navío escreví largo no diré más de que allá va en esta flota que acá queda Miguel Gerónimo... (Die private Korrespondenz spanischer Emigranten aus Amerika, 1574).

(31) ... la partida des ta flota . donde a pocos dias como alli llegue tuue nueuas de vno de esa tierra... (Cartas de particulares en Indias del siglo XVI, 1590).

(32) ... dare mill e quinientos ducados p[ar]a con q biban alla en españa . my hijo esta [en] balladolid ... (Cartas de particulares en Indias del siglo XVI, 1554).

(33) ... cayo en la mar y se ahogo y sacar?lo ahogado y alli en ocoa lo enterrar? dios le tenga en el sielo (Cartas de particulares en Indias del siglo XVI, 1577).

5 Sin embargo, no encontramos ningún ejemplo ni de aposición ni de combinaciones con el adjetivo mismo, relativamente habituales en el español actual. 


\subsection{Contraste}

Como recuerda Sedano $(1996,44)$, la hipótesis del contraste fue planteada inicialmente ya a finales del siglo XVIII por López de la Huerta $(1799,28 \mathrm{~s}$.) y, en tiempos mucho más recientes, ha sido defendida, entre otros, por Terrado (1990b, 49s.). Según estos autores, los adverbios en i se utilizan para dar cuenta de sentidos locativos o temporales absolutos, sin necesidad de ponerlos en relación con otras circunstancias. Por el contrario, las formas de la serie de á se asocian con entornos contrastivos. Los fragmentos de (34) a (37) ejemplifican de ambos contextos:

(34) ...yo le suplico me las mande trasladar, que me tiene allá cinco pesos de tipuzque, y también lo entiendo ... (El hilo que une, 1572).

(35) ... an de benir q por no tornar a llorar lo dejo y porq alli lo podra vm ber q en ber quan mal suçedido todo se me quita todo el sentido (Cartas de particulares en Indias del siglo XVI, 1587).

(36) ... que si ay [] falta de papel y tinta . por alla . porque yo se lo enbiare de aca para . que me escriua a mi señor juan de escobal... (Cartas de particulares en Indias del siglo XVI, 1568).

(37) ... enviar vmd. algo, que será como estar yo mismo allí para ponerlo aquí casi de valde. Fíe de mí, que (El hilo que une, 1585).

Distinto es el caso cuando ese contraste forma parte de un principio de idiomaticidad, en unidades fraseológicas en las que intervienen adverbios que ya están en buena medida debilitados sintácticamente. A propósito de esta cuestión, se ha observado que son los adverbios de la serie -á los más proclives a la formación de este tipo de combinaciones fraseológicas (Nilsson 1984, 233s.; Sedano 2000, 931s.; Company/Espinosa 2014, 205), quizá como un correlato de su supuesta mayor direccionalidad e imprecisa delimitación. En el corpus, encontramos también ejemplos de este tipo, como los ilustrados a continuación, en los que se puede apreciar la existencia real de variación. Sin embargo, dada su mínima representación (apenas siete casos), y al hecho de que en algunos de ellos no podamos estar seguros de la existencia de posible alternancia, finalmente no han sido considerados para el análisis cuantitativo:

(38) ... nunca e tenido asiento ni quietud sino sienpre de aca p [ar]a alla con muncho trabajo hasta agora (Cartas de particulares en Indias del siglo XVI, 1576).

(39) en esta tierra nunca esta un hombre en un cabo, sino siempre andando de aqui para alli, es cosa muy neçesaria, y por amor de dios... (Cartas de particulares en Indias del siglo XVI, 1587). 


\subsection{Priming}

Hasta donde llega nuestro conocimiento, en el estudio sobre la alternancia adverbial no se ha analizado la potencial influencia del priming estructural, esto es, la tendencia de los hablantes a utilizar material lingüístico que han empleado ya en el contexto inmediatamente anterior (Pereira-Scherre/Naro 1992; Labov 1994; Travis 2007; Pickering/Ferreira 2008). Para el caso que nos ocupa, este principio supondría, por ejemplo, que la presencia en el contexto previo ${ }^{6}$ de un adverbio de la serie en $i$ alentaría la selección de allí en el entorno inmediatamente siguiente. Y lo contrario: los adverbios de la serie en á desfavorecerían la elección de esa forma. En lo que sigue mostramos ejemplos ilustrativos de ambos contextos, así como de un tercero, el mayoritario en el discurso, y en el que no hay otros adverbios a la vista:

(40) ... rogandole le encaminase aqui y en el propio tienpo fue alli don pedro çores de ulloa el cual le reçivio en su serviçio (Cartas de particulares en Indias del siglo XVI, 1594).

(41) ... podía ser que allá se pusiese en decir que allí los perdió, enbío a vuestra merced con Miguel Martín... (Desde la otra orilla, 1555).

(42) ... V[uest]ras buenas oraciones y las de mys hermanas fueron tales que fue Dios servido de moverme el coraçón para enbarcarme para España, y así allegué hasta la Veracruz e allegado allí caydo doliente de unas calenturas que me truxeron al punto de la muerte y desahuciado de los médicos (Die private Korrespondenz spanischer Emigranten aus Amerika, 1578).

\subsection{Posición y adyacencia}

Algunas investigaciones sobre sintopías actuales han analizado la incidencia del factor posicional en la variación entre los adverbios de las series en á e í. Así, en su estudio sobre el habla de Caracas, Sedano (1996) observa que la selección de aquí (frente a acá) se ve favorecida extraordinariamente por la posición previa al verbo (95\%). Y lo mismo pasa con allí (frente a allá), solo que esta vez las proporciones son considerablemente menores (51\%). Sin embargo, el factor no es selec-

6 ¿Cómo de previo? En relación con esto, no hay una opinión unánime. Para algunos, el efecto del priming persiste por espacios tan extensos como el equivalente a diez verbos conjugados (Pickering/Ferreira 2008, 447), opinión maximalista que no compartimos. En nuestro caso, reducimos esa potencial influencia a las 25 palabras previas al adverbio, un límite que puede parecer arbitrario, pero que, como contrapartida, tiene la virtud de la objetividad. Lógicamente, los entornos de priming obtenidos con este criterio son mucho más reducidos, lo que, sin embargo, no resta interés al factor, como tendremos ocasión de comprobar (ver §4.3.1). 
cionado por el análisis de regresión logística en un estudio posterior en otra ciudad venezolana (Mérida), donde se estudia el contraste entre aquí y acá (Gallucci 2007). Con todo, en esta comunidad de habla las diferencias porcentuales se mueven en la misma dirección (en la selección de aquí: anteposición: 93\%; posposición: 83\%).

En el presente estudio analizamos también ese predictor, codificando como antepuestos los ejemplos de (43) y (44), y como pospuestos los de (45) y (46):

(43) ... se nos tomen todas las bulas de la cruzadas que vinieren. terné cuidado siempre de lo que allá toca y sólo suplico a vuestra merçed que me dexe de escrevir ... (Desde la otra orilla, 1555).

(44) ... que las trasegué a las bodegas de arriba y las rehenchí, y con todo esto se perdió ello y más de 30 arrobas del pueblo, que fue ario de esto; allí se gastó lo que Dios sabe y mi bolsa (El hilo que une, 1585).

(45) ... a perdido en acá y también dizen que no paresçe por allá. avnque quando esta llege sabrá de su pérdida. (Desde la otra orilla, 1556).

(46) ... escribió para Juan Gómez por los 35 pesos, y Ilamole allí y negolos. Escribiome el principal o cacique de aquel pueblo... (El hilo que une, 1584).

Finalmente, el condicionamiento sintáctico de la variable se completa con el grado de adyacencia respecto al elemento del que es complemento el adverbio, y que, como se recordará, es casi siempre el verbo. De este modo, en el análisis cuantitativo distinguimos entre contextos adyacentes como los de (47) y (48), y no adyacentes, como en (49) y (50). Hasta donde sabemos, se trata de un predictor inexplorado en el estudio sobre la variación entre los adverbios demostrativos:

(47) ... pues todo era para su casa servicio y dexar descansar lo que allá está en poder de vuestra merçed (Desde la otra orilla, 1537).

(48) ... y así allegué hasta la Veracruz e allegado allí caydo doliente de unas calenturas que me truxeron al punto de la muerte (Die private Korrespondenz spanischer Emigranten aus Amerika, 1578).

(49) ... digan que hellos escriuieron al señor mariscal desde allá pidiéndole este favor (Desde la otra orilla, 1547).

(50) ... si Dios quisiere, enviar vmd. algo, que será como estar yo mismo allí para ponerlo aquí casi de valde (El hilo que une, 1585).

\subsection{Factores extralingüísticos}

En los estudios sobre la alternancia adverbial en sintopías actuales, esta se ha puesto en relación con diversos factores extralingüísticos, entre los que destacan el eje dialectal, y en menor medida, el sociolectal (Rodríguez 1994). En relación con el primero, se han advertido algunas preferencias por los subsistemas en $a ́ \mathrm{y}$ 
en $i$ a uno y otro lado del océano. Así, se ha señalado que las primeras formas aparecen más frecuentemente en regiones americanas que en el español europeo (Kany 1945/1969, 319; Alvar/Pottier 1983; 331s.; Sedano 2000; RAE/ASALE 2009, $\S 17.8 \mathrm{~cd})$. Con todo, a partir de los materiales recogidos en el corpus CREA correspondientes a los años 2000 y 2001 en cuatro países de habla hispana (Argentina, España, México y Uruguay), y en todos los géneros textuales, Company/Espinosa $(2014,188)$ encuentran una presencia abrumadora de las formas en -i en todas las regiones, aunque con una diferencia favorable a España (87\%) respecto a Latinoamérica (75\%). Sin embargo, incluso en esta última cabe apreciar una distancia notable entre los valores correspondientes a México (90\%), más cercanos, pues, a los españoles, y los de países del Cono Sur del continente, donde las frecuencias de los adverbios en -á aumentan. Aun así, en el estudio de Sedano (1996) sobre el español de Caracas, las proporciones de allá (72\%) son significativamente mayores que las de alli (28\%). ${ }^{7}$

Por otro lado, en el plano diacrónico, García/Colomé (2012) señala que este mayor empleo relativo de las formas en á comenzó ya a extenderse durante las primeras décadas del siglo XVI, llevado a América por los emigrantes españoles, que en la época eran mayoritariamente andaluces y extremeños. A partir de entonces se convertiría en un americanismo que singularizaba las hablas americanas frente a las españolas, y que se habría acrecentado con el paso del tiempo.

Para poner a prueba estas hipótesis, en el presente estudio analizamos la potencial incidencia de dos factores extralingüísticos. En primer lugar, y siempre que la información estuviera disponible, agrupamos las ocurrencias de la variable de acuerdo con la procedencia geográfica de los escritores. Aunque sobre este factor existen algunas lagunas en el corpus, lo que nos impide incluirlo en el análisis de regresión logística junto a los demás, contamos con un número significativo de ejemplos de algunos entornos dialectales, como Andalucía, Extremadura, Castilla la Vieja, Castilla la Nueva y las regiones vasco-navarras. Ello nos permitirá evaluar, siquiera superficialmente, las eventuales diferencias entre esos grupos. Por otro lado, con el origen del documento, queremos considerar también la hipótesis del americanismo de las formas en -á, al comparar los textos escritos desde América por inmigrantes españoles sometidos a un intenso - $-\mathrm{y}$, a menudo, duradero- contacto interlectal, y aquellos que se escribieron en España, en condiciones sociales más convencionales. Al tiempo, ello nos permitirá considerar otras hipótesis acerca de la variación y el cambio lingüístico, como las que se han propuesto a propósito de la koinización y demás procesos de simplificación en condiciones sociales excepcionales como las descritas.

7 No así en el par aquí/acá, donde el primero supera (88\%) ampliamente al segundo (12\%). 
Junto a estos dos factores, el cuadro de condicionantes extralingüísticos se completa con tres predictores adicionales. Dos de ellos son clásicos en la investigación sociolingüística: el sexo y el estatus social de los escritores. Por lo que al primero se refiere, hay que advertir que el corpus está sumamente desequilibrado, con muestras femeninas que apenas rebasan el 13\% de los datos disponibles. En cuanto al estatus, hay que destacar la aparición en este corpus de una mayoría de escritores de condición social humilde, que escribieron o dictaron cartas a sus allegados a uno y otro lado del Atlántico, implorando la reunificación familiar o relatando innumerables peripecias vitales que habían tenido lugar desde la ya lejana separación. Con todo, entre estos escritores los hay también de una condición social más elevada, como terratenientes, tesoreros, mercaderes, obispos, capellanes, médicos, licenciados, etc. De este modo, el continuum sociolectal queda dividido en dos grupos, que denominamos Bajo y Alto por razones puramente expositivas.

Por último, el tipo de relación nos informa acerca de tres niveles de solidaridad entre los interlocutores y de la potencial influencia de este factor socio-estilístico: cercana, para la comunicación epistolar entre miembros de la familia nuclear (padres e hijos, hermanos, etc.), intermedia, en el que se recogen las cartas dirigidas entre simples conocidos o entre miembros lejanos de una familia, a los que no unen los mismos lazos de afectividad que a los anteriores; y distante, en la interlocución entre personas, muchas veces desconocidas, que escriben cartas por motivos básicamente instrumentales (dar cuenta del fallecimiento de un familiar, de las últimas voluntades de este, solicitar el pago de una deuda, dar detalles comerciales, etc.).

Finalmente, el análisis se completa con el concurso de un factor continuo, el año en que se escribieron los textos, el cual nos permitirá evaluar la existencia o no de un cambio lingüístico en la distribución de las formas adverbiales a lo largo de la centuria. Además, todos los predictores considerados, tanto categóricos como continuos, serán filtrados a través de un factor aleatorio, el autor de las cartas, con el objeto de comprobar si las tendencias de agrupación de los factores categóricos, tanto en el plano lingüístico como extralingüístico, resisten o no el posible sesgo introducido por las preferencias idiolectales. 
Tabla 1: Resumen y tipología de los factores considerados en el análisis

\begin{tabular}{|c|c|c|c|}
\hline Predictores & Factores & Breve descripción & Carácter \\
\hline Delimitación & $\begin{array}{l}\text { Preciso } \\
\text { Impreciso }\end{array}$ & $\begin{array}{l}\text { Sentido referencial específico o vago del } \\
\text { adverbio }\end{array}$ & Categórico \\
\hline $\begin{array}{l}\text { Direccionali- } \\
\text { dad }\end{array}$ & $\begin{array}{l}\text { Origen } \\
\text { Destino } \\
\text { Tránsito } \\
\text { Estado }\end{array}$ & $\begin{array}{l}\text { Tipo de dirección expresada por el } \\
\text { adverbio }\end{array}$ & Categórico \\
\hline Preposición & $\begin{array}{l}\text { Sí } \\
\text { No }\end{array}$ & Presencia/ausencia de preposición & Categórico \\
\hline Tipo de verbo & $\begin{array}{l}\text { Estado } \\
\text { Lengua } \\
\text { Acción } \\
\text { Movimiento }\end{array}$ & $\begin{array}{l}\text { Modo de acción del verbo con el que se } \\
\text { asocia el adverbio }\end{array}$ & Categórico \\
\hline Función & $\begin{array}{l}\text { Comp. Verbo } \\
\text { Otras }\end{array}$ & Función sintáctica del adverbio & Categórico \\
\hline Combinatoria & $\begin{array}{l}\text { Complemento } \\
\text { No }\end{array}$ & $\begin{array}{l}\text { (In)existencia de complementos del } \\
\text { adverbio }\end{array}$ & Categórico \\
\hline Contraste & $\begin{array}{l}\text { Sí } \\
\text { No }\end{array}$ & $\begin{array}{l}\text { (In)existencia de oposición de sentido } \\
\text { con los adverbios de proximidad (acá, } \\
\text { aquí) en el contexto inmediato }\end{array}$ & Categórico \\
\hline Priming & $\begin{array}{l}\text { Formas en }-a \\
\text { Formas en }-i \\
\text { No }\end{array}$ & $\begin{array}{l}\text { Presencia de otras formas adverbiales } \\
\text { en el contexto previo }\end{array}$ & Categórico \\
\hline Posición & $\begin{array}{l}\text { Antepuesto } \\
\text { Pospuesto }\end{array}$ & Emplazamiento con respecto al verbo & Categórico \\
\hline Adyacencia & $\begin{array}{l}\text { Adyacente } \\
\text { No adyacente }\end{array}$ & $\begin{array}{l}\text { Grado de adyacencia con respecto al } \\
\text { verbo }\end{array}$ & Categórico \\
\hline Relación & $\begin{array}{l}\text { Estrecha } \\
\text { Intermedia } \\
\text { Distante }\end{array}$ & Tipo de vínculo con el destinatario & Categórico \\
\hline Sexo & $\begin{array}{l}\text { Hombre } \\
\text { Mujer }\end{array}$ & Sexo del autor & Categórico \\
\hline Estatus & $\begin{array}{l}\text { Alto } \\
\text { Bajo }\end{array}$ & Estrato social del autor & Categórico \\
\hline $\begin{array}{l}\text { Origen docu- } \\
\text { mento }\end{array}$ & $\begin{array}{l}\text { América } \\
\text { Europa }\end{array}$ & Lugar en el que se escriben las cartas & Categórico \\
\hline Procedencia & Regiones & Origen del remitente & \\
\hline Fecha & Años & Año en que se redactan las cartas & Continuo \\
\hline Informante & Nombre del remitente & Identidad del remitente & Aleatorio \\
\hline
\end{tabular}




\section{Corpus y metodología}

Como se sugiere al inicio, la actual investigación se encuadra en las coordenadas de un proyecto de investigación dedicado al estudio de la variación y del cambio lingüístico en español por medio de las herramientas de la sociolingüística histórica. Como elemento central para su articulación, debemos destacar la compilación de un corpus suficientemente amplio de textos escritos que presuponemos más próximos a la inmediatez comunicativa (Oesterreicher 2004). Con él, hemos tratado de neutralizar uno de los más importantes problemas metodológicos con los cuales topa de modo tradicional el estudio histórico: la ausencia de corpus suficientemente amplios y representativos de la oralidad de tiempos pasados (cf. Labov 1994, 11; Nevalainen/Raumolin-Brunberg 2003, 26s.; Hernández-Campoy/ Schilling 2012, 64-75).

En ese sentido, podemos señalar el género epistolar como una de las tradiciones discursivas juzgadas comúnmente como más próximas a esa oralidad y, por ende, más adecuadas para la investigación diacrónica. Y esto es especialmente interesante cuando se trata de cartas privadas, cuyos remitentes son particulares de diferente naturaleza y extracción (Oesterreicher 2004; Palander-Collin/Nevala 2005; Elspaß 2012; Schneider 2013). En el contexto español, el periodo estudiado supone además un hito relevante para el género, pues coincide con el momento culminante de la conquista y colonización de América. Ello supuso el envío constante de cartas a uno y otro lado del Atlántico. Estas epístolas, escritas por españoles de diferentes procedencias sociales y dialectales a lo largo todo un siglo conforman, precisamente, la parte más extensa del corpus.

Desde una perspectiva estilística, el corpus nos ofrece una diversidad relevante, muy prometedora para nuestro propósito de estudio, pues su temática considera asuntos variados, desde el tratamiento de cuestiones íntimas y familiares en un extremo, a motivos menos cercanos al ámbito personal en el otro. Además, por sus condiciones estructurales, las cartas aportan testimonios valiosos para el análisis sociolingüistico, en la medida que van acompañadas de detalles autobiográficos en los cuales se vislumbran las relaciones de solidaridad y poder entre los interlocutores, así como datos acerca del estatus social de los remitentes y la vida diaria del momento en que concibieron sus misivas (Raumolin-Brunberg 2005; Dossena/Tieken-Boon van Ostade 2008; Nevala 2009; Okulska 2010). Finalmente, y quizá esto sea lo más importante, es plausible pensar que puedan considerarse entre las tradiciones discursivas más cercanas al habla vernácula de épocas pretéritas, y de las que no conservamos testimonios puramente orales; y esto es así porque, en su planteamiento inicial, no se escribieron con la intención de ser publicadas (Palander-Collin/Nevala 2005). En este sentido, como indica Cano (1996), las cartas muestran también cierta rigidez estructural (ligada, especial- 
mente, a los encabezamientos y los cierres epistolares); sin embargo, otros rasgos las configuran como un terreno abonado para el análisis sociolingüístico. De este modo ocurre, en nuestro corpus, con la presencia de no pocos autores provenientes de estratos sociales lejanos de las elites, y, por lo tanto, sin representación en los géneros textuales más formales, que han servido tradicionalmente como testigo para la lingüística histórica. Por otro lado, las cartas se destinan en muchas ocasiones a la expresión de todo tipo de afectos y sentimientos, y eso hace esperable un nivel de planificación significativamente menor que en otros textos escritos. Como ha señalado con acierto García Mouton (1999, 264), «los textos literarios pueden imitar la realidad; las cartas, aun sometidas a todo tipo de molde, forman parte de ella».

Como se puede ver en la tabla 2, el corpus seleccionado para la ocasión está compuesto por 895 cartas, escritas por 670 individuos diferentes a lo largo de todo el siglo XVI, si bien no disponemos de muestras anteriores a 1528. Todo ello representa un volumen de registros que supera el medio millón de palabras. Las cartas se han extraído de cuatro obras publicadas en los últimos años a cargo de otros tantos autores, que han recogido un valioso material para el estudio lingüístico. Se trata de las siguientes (en la tabla 2 puede verse el número de escritores y cartas compilados en cada caso):

Sánchez Rubio, Rocío/Testón Núñez, Isabel, El hilo que une. Las relaciones epistolares en el Viejo y el Nuevo Mundo, siglos XVI-XVIII, Mérida, Universidad de Extremadura, 1999.

Martínez Martínez, María del Carmen (ed.), Desde la otra orilla. Cartas de Indias en el Archivo de la Real Chancillería de Valladolid, siglos XVI-XVIII, León, Junta de Castilla y León, 2007.

Fernández Alcaide, Marta, Cartas de particulares en Indias del siglo XVI. Edición y estudio discursivo, Frankfurt, Vervuert, 2009.

Stangl, Werner, Zwischen Authentizität und Fiktion. Die private Korrespondenz spanischer Emigranten aus Amerika, 1492-1824, Wien/Köln/Weimar, Böhlau, 2012.

La compilación de Fernández Alcaide (2009), que revisa exhaustivamente una anterior del historiador hispano-alemán Enrique Otte (1988), es la más respetuosa con los textos originales. Las otras tres corresponden a la obra de sendos historiadores sociales que han estudiado el fenómeno de la migración a América, y que en la edición de los textos realizan algunas modernizaciones para facilitar su lectura. Con todo, estas afectan solo al plano ortográfico, lo cual supondría, obviamente, un importante obstáculo para estudios del nivel fónico o gráfico (Hebda 2012), pero no para otros de carácter gramatical como el presente. Por otro lado, 
algunos autores han llamado la atención sobre un hecho que afecta a los textos epistolares del siglo XVI y es que a menudo -y especialmente en las clases subalternas- no están escritos de su puño y letra, sino dictados y trasladados al papel por escribanos (Fernández Alcaide 2009; Bergs 2012). Pese a ello, algunos estudios han comprobado que la influencia de este hecho pudo ser mucho menos determinante de lo que aparenta, el menos en niveles profundos del análisis. A este respecto, Bergs (2005) recuerda, por ejemplo, cómo en las cartas privadas escritas por miembros de la familia Paston entre los siglos XVI y XVII, la morfosintaxis de los diversos autores es significativamente diferente entre sí, y ello pese a que todas fueron dictadas a un único escribano. Por nuestra parte, en un estudio sobre la variación entre las perífrasis verbales deber y deber de + infinitivo en textos epistolares del XVI, vimos también cómo la gramática interna de la variación era singularmente parecida cuando comparamos los textos autógrafos y el resto.

Tabla 2: Algunas cifras del corpus epistolar

\begin{tabular}{lccc}
\hline Epistolarios & Cartas & Escritores & N. palabras \\
\hline Cartas de particulares & 640 & 516 & 427.242 \\
\hline El hilo que une & 144 & 89 & 89.831 \\
\hline Desde la otra orilla & 67 & 22 & 55.667 \\
\hline $\begin{array}{l}\text { Die private } \\
\begin{array}{l}\text { Korrespondenz spa- } \\
\text { nischer Emigranten } \\
\text { aus Amerika }\end{array}\end{array}$ & 44 & 43 & 24.177 \\
\hline \begin{tabular}{l} 
Total \\
\hline
\end{tabular} & 895 & 670 & 596.917 \\
\hline
\end{tabular}

Para el análisis cuantitativo, en el que tomamos la forma allí como variante de referencia, ${ }^{8}$ efectuamos un análisis de regresión logística de efectos mixtos mediante el programa Rbrul (Johnson 2009), el cual nos permite analizar la incidencia del eje temporal en el cambio lingüístico, así como estimar la significación independiente de los diferentes predictores fijos considerados (véase la relación en §2), junto con sus potenciales interacciones. Además, el programa Rbrul permite analizar la consistencia de este conjunto de datos tomando como referencia

8 Lo hacemos así, en lugar de poner el foco en la variante mayoritaria (allá), por tratarse de la forma adverbial que va ganando usos conforme avanza la centuria, en un claro proceso de cambio lingüístico. 
los factores aleatorios antes señalados; esto ofrece a los resultados una destacable mayor solidez, pues concede significación estadística únicamente a los predictores fijos en los cuales el efecto es suficientemente fuerte como para salvar las potenciales desviaciones ideolectales (Johnson 2009, 365).

Por otro lado, además de las frecuencias absolutas y relativas (porcentajes), el análisis multivariante nos permite utilizar diferentes procedimientos de prueba con los cuales evaluamos la relevancia de los condicionantes analizados. Son los siguientes:

a) el elenco de predictores seleccionados y no seleccionados por el modelo de regresión;

b) la relevancia explicativa de los predictores seleccionados, derivada del rango pertinente; ${ }^{9}$

c) la significación estadística de los distintos factores de cada predictor, ofrecida bajo la forma de pesos explicativos o valores P. ${ }^{10}$

d) la jerarquía explicativa, o dirección del efecto, que va desde el entorno más favorecedor al más desfavorecedor.

\section{Resultados y análisis}

\subsection{Generales}

La muestra consta de 1233 ocurrencias de la variable, de las cuales 962 (78\%) corresponden a la variante allá y $271(22 \%)$ a allí. Como se puede ver, estas cifras absolutas suponen una primera diferencia notable con lo apuntado en investigaciones previas, que, como se recordará, hablan de una primacía considerable del adverbio allí en toda la historia del español. La clave, a nuestro juicio, puede estar en la diferente tipología textual sobre la que se realizan esos recuentos. Así, en

9 El rango es una medida no estadística a la que se llega restando las significaciones de los contextos más favorecedores y de los más inhibidores, respectivamente.

10 Los resultados de estas pruebas se ofrecen bajo la forma de pesos probabilísticos (valores P.). Estos se sitúan entre los extremos del 0 (nulo favorecimiento de una variante) y el 1 (selección categórica de esa variante). Habitualmente, se asume que los valores por encima .50 señalan factores favorecedores de una variante concreta, mientras que aquellos que se sitúan bajo de ese umbral la desfavorecen. Sin embargo, algunos autores juzgan que lo más importante es el sentido explicativo de esos indicadores, por encima de las cifras concretas (Tagliamonte 2012, 173). Por otro lado, el formato con que se ve en las tablas la incidencia de los factores continuos, como el tiempo, es distinto. Se apreciará, en estos casos, que los indicadores no muestran valores P. sino logaritmos de verosimilitud. 
relación con los textos del CORDE, en los que se han basado algunos cómputos recientes, Company/Espinosa $(2014,180)$ señalan lo siguiente:

«...propician allí porque son básicamente narrativos y el narrador se sitúa en la distancia por lo general, de manera que alli es la forma ideal para expresar esa distancia, y, por otra, a que este adverbio puede funcionar como fórico mucho mejor que aquí, que es, esencialmente deíctico, y la lengua escrita contiene un mucho mayor número de expresiones fóricas, pues deja aflorar la oralidad con dificultad, dificultad que se incrementa cuando se trata de manifestar actos de habla deícticos».

Aunque la cita de estas autoras alude a la preminencia de allí sobre aquí en la historia, algunos de sus argumentos pueden valer para la discusión actual. En efecto, por su propia naturaleza, los textos narrativos propician las ocurrencias fóricas de los adverbios. Pero ¿qué ocurre con un género como las cartas privadas? En ellas no faltan, ciertamente, pasajes narrativos, pero estos alternan continuamente con fragmentos donde el remitente establece un diálogo con el destinatario, cuyas coordenadas espacio-temporales se actualizan deícticamente mediante el empleo de los adverbios. Solo que estas referencias al emplazamiento del destinatario no se realizan mayoritariamente mediante el empleo de allí, sino a través de allá.

Asimismo, conviene llamar la atención acerca de la existencia de un cambio en la distribución de los adverbios a lo largo de la centuria, tendencia que se ve confirmada tras la selección del eje temporal en el análisis de regresión (ver más adelante tabla 4). Agrupados los datos en periodos de veinte años, la tabla $3 \mathrm{y}$ también representado en el Gráfico 1, muestran la existencia de varios momentos en esa evolución. Así, durante las seis primeras décadas del siglo, ${ }^{11}$ las cifras se mantienen en niveles muy estables (cercanos al 15\%). Sin embargo, a partir de 1570, los números de allí comienzan a aumentar, en una tendencia ascendente que se agudiza en la última década. De esta manera, en los albores del siglo XVII, las proporciones de allí alcanzan ya el 32\%, doblando así las halladas durante la primera parte de la centuria.

11 Como se recordará, no disponemos de muestras correspondientes a las dos primeras décadas del siglo. 
Tabla 3: Frecuencias de las variantes adverbiales por periodos (siglo XVI)

\begin{tabular}{lccccc}
\hline & Allí & \multicolumn{3}{c}{ Allá } & $\boldsymbol{\Sigma}$ \\
\hline & $\mathbf{N}$ & \% & N & \% & N \\
\hline $\mathbf{1 5 3 0 - 1 5 5 0}$ & 9 & 15 & 48 & 85 & 57 \\
\hline $\mathbf{1 5 5 1 - 1 5 7 0}$ & 39 & 13 & 267 & 87 & 306 \\
\hline $\mathbf{1 5 7 1 - 1 5 9 0}$ & 189 & 25 & 576 & 75 & 765 \\
\hline $\mathbf{1 5 9 1 - 1 6 0 0}$ & 34 & 32 & 71 & 68 & 105 \\
\hline Total & 271 & 22 & 962 & 78 & 1233 \\
\hline
\end{tabular}

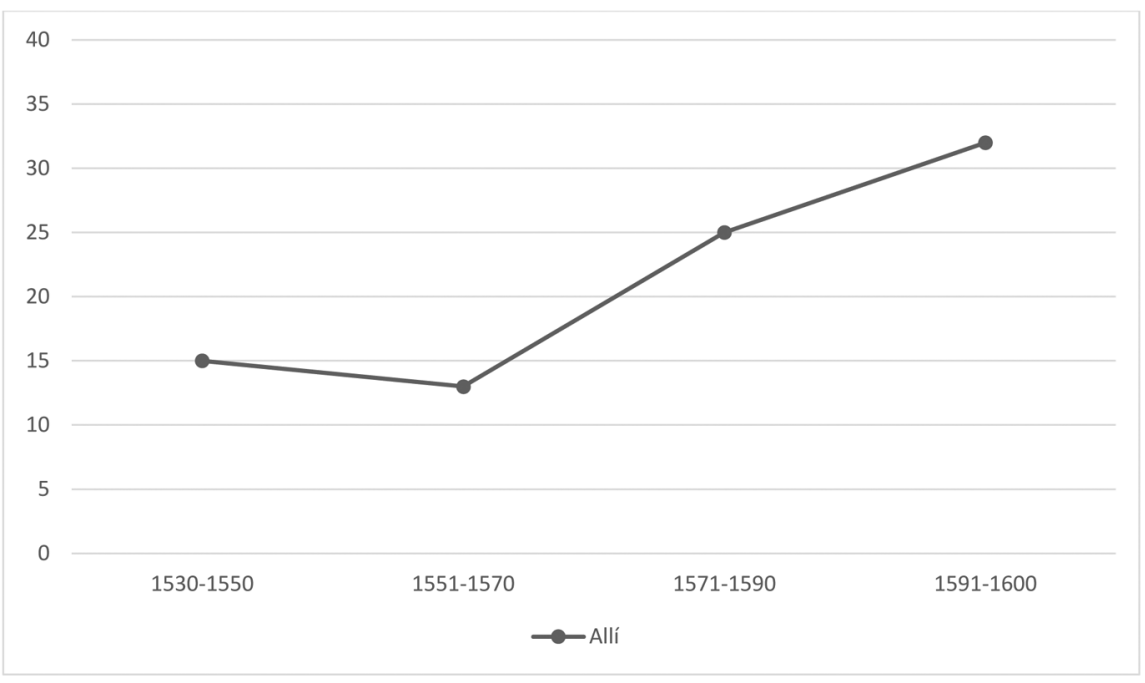

Gráfico 1: Evolución de los usos de allí por periodos (siglo XVI).

\subsection{Variación idiolectal}

De los 670 escritores que integran el corpus, hallamos muestras de la variable en 405 escritores (60\%), una cifra elevada para tratarse de una variable gramatical, pero que se justifica por las características del marco comunicativo al que remiten las cartas, y que favorece la presencia de elementos deícticos como los adverbios demostrativos. Aun así, de estos 405 autores, solo en 130 (31\%) aparece la forma allí. Por el contrario, en los 275 (69\%) restantes, únicamente advertimos allá. Ello no significa, obviamente, que ante una muestra mayor no pudiéramos encontrar 
en ellos manifestaciones de los dos adverbios, pero el desequilibrio entre uno grupo y otro es revelador acerca de las notables diferencias en la distribución de los adverbios durante el siglo XVI. Más aún si consideramos que de ese centenar largo de escritores en cuyas cartas encontramos muestras de allí, tan solo 43 (34\%) usan categóricamente esta forma, mientras que los otros 87 (64\%) utilizan las dos variantes en la redacción. Por otro lado, los argumentos para afirmar ese uso categórico son débiles, pues en la mayoría de los casos (29) la selección de este adverbio se reduce a una única ocurrencia.

Lo anterior justifica que sean muy escasos los ejemplos de escritores como los castellanos Pedro Gómez de Montejo (5 de 5) o Esteban Marañón (6 de 6), que escriben varias cartas desde América. Y no digamos el caso totalmente excepcional del madrileño Celedón Favalis, quien en una extensa carta a su padre ${ }^{12}$ utiliza nada menos que $23(75 \%)$ ejemplos de allí, frente a tan solo $8(25 \%)$ de la forma contraria. Por el contrario, son mucho más corrientes los casos inversos, esto es, los escritores que seleccionan cuasi categóricamente la forma allá. Sin ánimo de ser exhaustivos, así ocurre, por ejemplo, en las cartas de los andaluces Bartolomé de Morales y Segundo Martínez (10 de 10 en ambos casos), el vasco Francisco Ortiz de Aulestia (11 de 11), el terrateniente y ganadero castellano Andrés Chacón (14 de 14) o el mercader andaluz, Luis de Córdoba en una carta a su mujer (17 de 17). Con todo, más reveladores son aún los ejemplos de otro castellano, Francisco Rodríguez Santos, tesorero de la catedral de México, quien a lo largo de diez cartas dirigidas a diversos miembros de su familia, utiliza en 26 ocasiones el adverbio allá y solo una la forma allí.

\subsection{Análisis de la gramática interna}

En este apartado examinamos los principales resultados derivados del análisis de regresión logística de efectos mixtos que hemos llevado a cabo, y cuyos datos más relevantes aparecen a continuación en la tabla 4. Como se recordará, en ella se toma como objeto de atención la forma allí, minoritaria en términos generales, pero con una evolución ascendente conforme avanza la centuria.

12 En realidad, se trata de dos; la segunda es copia de la primera con algunas variaciones formales (que, en lo esencial, no afectan a los adverbios que nos interesan) como recuerda Fernández Alcaide $(2009,528)$. 
Tabla 4: Distribución de los factores analizados en la selección de la variante allí en el corpus

\begin{tabular}{|c|c|c|c|c|}
\hline FACTORES & $\mathbf{N}$ & $\%$ & $\Sigma$ & P. \\
\hline \multicolumn{5}{|l|}{ Delimitación } \\
\hline Preciso & 209 & 46 & 448 & .78 \\
\hline Otras & 62 & 8 & 785 & .21 \\
\hline \multicolumn{5}{|l|}{ Sentido } \\
\hline Origen & 69 & 36 & 192 & .76 \\
\hline Estativo & 162 & 24 & 683 & .61 \\
\hline Destino & 34 & 15 & 232 & .43 \\
\hline Tránsito & 6 & 5 & 126 & .21 \\
\hline \multicolumn{5}{|l|}{ Posición } \\
\hline Antepuesto & 136 & 25 & 543 & .59 \\
\hline Pospuesto & 135 & 19 & 690 & .41 \\
\hline \multicolumn{5}{|l|}{ Contraste } \\
\hline Sí & 11 & 7 & 166 & .22 \\
\hline No & 260 & 24 & 1067 & .78 \\
\hline \multicolumn{5}{|l|}{ Priming } \\
\hline Formas en_i & 14 & 40 & 35 & .87 \\
\hline No & 253 & 23 & 1096 & .37 \\
\hline Formas en_a & 4 & 4 & 102 & .20 \\
\hline \multicolumn{5}{|l|}{ Tipo de verbo } \\
\hline Estado & 131 & 20 & 644 & -13 \\
\hline Lengua & 22 & 23 & 94 & - \\
\hline Acción & 42 & 28 & 150 & - \\
\hline Movimiento & 76 & 22 & 345 & - \\
\hline \multicolumn{5}{|l|}{ Preposición } \\
\hline Sí & 81 & 24 & 339 & - \\
\hline No & 190 & 21 & 894 & - \\
\hline \multicolumn{5}{|l|}{ Adyacencia } \\
\hline Adyacente & 144 & 20 & 714 & - \\
\hline No adyacente & 127 & 24 & 519 & - \\
\hline
\end{tabular}

13 Con los guiones damos cuenta de que los predictores correspondientes (tipo de verbo, preposición, adyacencia, etc.) no han sido seleccionados como significativos por el análisis de regresión. 


\begin{tabular}{|c|c|c|c|c|}
\hline \multicolumn{5}{|l|}{ Función } \\
\hline Compl. verbo & 222 & 22 & 1159 & - \\
\hline Otras & 11 & 15 & 74 & - \\
\hline \multicolumn{5}{|l|}{ Combinatoria } \\
\hline Complemento & 13 & 28 & 46 & - \\
\hline No & 258 & 22 & 1187 & - \\
\hline \multicolumn{5}{|l|}{ Relación } \\
\hline Cercana & 188 & 23 & 794 & - \\
\hline Intermedia & 41 & 17 & 234 & - \\
\hline Distante & 42 & 20 & 205 & - \\
\hline \multicolumn{5}{|l|}{ Sexo } \\
\hline Hombres & 248 & 23 & 1094 & - \\
\hline Mujeres & 23 & 16 & 139 & - \\
\hline \multicolumn{5}{|l|}{ Estatus } \\
\hline Bajo & 190 & 24 & 789 & - \\
\hline Alto & 79 & 18 & 444 & - \\
\hline \multicolumn{5}{|c|}{ Origen documento } \\
\hline América & 244 & 22 & 1093 & - \\
\hline España & 27 & 19 & 140 & - \\
\hline \multicolumn{4}{|c|}{ Año (continuous logodds) } & +10.023 \\
\hline
\end{tabular}

$n=1233$; intercept: -42.697 ; overall proportion: 0.22; log.likelihood: -429.308 ; AICc: 880.832 ; Dxy.total: 0.90

\subsubsection{Factores seleccionados}

A la luz de la muestra disponible, en el siglo XVI la variación entre allí y allá se ve condicionada por factores semánticos (delimitación y sentido), sintácticos (posición) y discursivos (contraste y priming). Ninguno de los demás, ni lingüísticos, ni extralingüísticos, muestra la suficiente robustez como para ser seleccionado por el programa de regresión, y de hecho, las diferencias frecuenciales halladas entre los correspondientes grupos son escasas o mínimas (de lo más relevante de este bloque de factores no seleccionados nos ocuparemos más adelante en §4.3.2).

En cabeza de los predictores que sí explican la variación se encuentra el que hemos denominado delimitación, y que, como se recordará (ver §2.1), sitúa las coordinadas espaciotemporales alejadas del hablante bien de una manera precisa y explícita en el contexto inmediato, bien de forma vaga e imprecisa, aunque a 
menudo se intuya que alude a la ubicación del destinatario de la carta. Pues bien, el análisis de regresión no deja lugar a dudas: los emplazamientos precisos favorecen notablemente la selección de alli (46\%; .78), frente a los imprecisos, que se revelan mucho más adversos $(8 \% ; .21)$.

Un segundo factor semántico relevante es la direccionalidad. De acuerdo con este, distinguimos entre contextos estativos, que la tradición gramatical ha supuesto asociados a las formas en -í, y dinámicos, vinculados a los adverbios en -á. Con todo, dentro de este distinguíamos varios subtipos en función de la clase de movimiento que describen: origen, destino y tránsito. Los resultados del análisis empírico tan solo avalan parcialmente los postulados de esa tradición gramatical, al confirmar una asociación positiva entre los entornos estativos y el adverbio allí. Aun así, obsérvese cómo esa asociación se produce solo por comparación con el resto de contextos, ya que, en términos absolutos, los estados se reproducen en el corpus mucho más mediante la forma allá (76\%) que a través el adverbio alli (24\%). Por otro lado, la idea de que la direccionalidad está unida indisolublemente a allá se cumple también de manera solo parcial. Así, aunque es verdad que esta forma es mayoritaria en todos los contextos direccionales considerados, y especialmente en la expresión del tránsito (95\%) y el destino (85\%), las cosas son distintas en la expresión del origen del movimiento. En estos casos, la variante allí encuentra una de sus principales vías de penetración en el sistema (36\%; .76). Por el contrario, el destino (15\%; .43) y, sobre todo, el tránsito (5\%; .21) representan todavía contextos muy desfavorables para la forma en $i$ en el siglo XVI.

Los materiales de esta centuria confirman también la pretendida asociación entre los entornos contrastivos (entre adverbios de cercanía y lejanía, del tipo «acá hace frío, allá calor», «allí iremos nosotros y aquí se quedarán ustedes») y la forma allá, y los absolutos, o no contrastivos, y el adverbio allí. En efecto, los casos de contraste semántico con otros adverbios de cercanía desfavorecen sobremanera la selección de allí (7\%; .22), mientras que los usos no contrastivos son mucho más amigables $(24 \% ; .78)$. Con todo, no conviene perder de vista de nuevo el prisma bajo el que se deben interpretar estos datos. En la práctica, los datos del XVI no avalan lo dicho por la bibliografía, ya que incluso en los empleos absolutos, no contrastivos, la selección de allá es claramente mayoritaria (76\%). Lo único que podemos afirmar es que, en la comparación entre ambos entornos, uno es mucho más favorable que otro para la expansión de la variante minoritaria, allí.

Otro factor discursivo que se ha revelado explicativo es el priming estructural, y ello pese a las irregularidades muestrales entre los diferentes grupos considerados. De esta manera, comprobamos cómo la presencia en el entorno previo de otro adverbio de la serie en $-i$, representa un contexto muy favorecedor para la 
elección posterior de allí (40\%; .87). Todo lo contrario que aquellos casos en los que esa forma previa corresponde a un elemento de la serie en -á: tan solo en el $4 \%$ (.20) de las ocasiones en que se produce este hecho, vemos seguidamente una ocurrencia de allí.

Finalmente, la variación se ve influida también - aunque en menor medida, a la luz de los estadísticos obtenidos-, por un factor sintáctico cuya incidencia se ha estudiado en algunas sintopías actuales: la posición del adverbio. Y al igual que en ellas, en las cartas del XVI comprobamos una asociación positiva entre la anteposición del adverbio $(25 \%$; .59) y la forma alli, frente a la posposición, que representa un entorno más hostil $(19 \% ; .41)$. Ahora bien, como otras veces, las diferencias son siempre relativas, no absolutas. De esta manera, si en el corpus de Caracas estudiado por Sedano (1996), alli alcanza el 51\% en la anteposición, en los textos del XVI estas proporciones se quedan en la mitad (25\%), revelando que también aquí la variante no marcada, y mayoritaria, era allá.

\subsubsection{Factores no seleccionados}

Como avanzábamos en el apartado anterior, ningún otro factor ha revelado fuerza suficiente para explicar la variación. Uno de ellos es la presencia o ausencia de preposición, que, al decir de algunos autores (ver 2.3), es sensible a la selección de las series formales en -í y en -á en la historia del español. Como se aprecia en la tabla 5, salvo un ejemplo aislado con la preposición en (que selecciona allá), todas las demás aparecen con los dos adverbios, aunque en proporciones diferentes. De mayor a menor, y salvadas las considerables diferencias muestrales entre unas preposiciones y otras, estos son los porcentajes alcanzados por las combinaciones con allí: hasta (75\%), desde (68\%), de (32\%), para (20\%), por (5\%). Estos cómputos revelan algunas diferencias con respecto a las tendencias advertidas por Company/Espinosa (2014, 203). En su corpus, por ejemplo, las preposiciones desde, hasta y para solo anteceden a los adverbios en -í, inclinación categoría que difiere de lo observado en muestra epistolar del siglo XVI, especialmente en el caso de para. ${ }^{14}$ Asimismo, en nuestro corpus por es la preposición más asociada con allá, a diferencia de la muestra manejada por estas autoras, donde «es la preposición de mayor empleo con ambas series» (ib.).

14 La misma tendencia favorable a la selección de allá con la preposición para han advertido Sedano (2000) y RAE/ASALE (2009, n§17.8g) en el español actual. 
Tabla 5: Distribución de las preposiciones que rigen allí en el corpus

\begin{tabular}{lccc}
\hline Preposición & N & \% & $\boldsymbol{\Sigma}$ \\
\hline De & 54 & 32 & 170 \\
\hline Desde & 15 & 68 & 22 \\
\hline En & 1 & 100 & 1 \\
\hline Hasta & 3 & 75 & 4 \\
\hline Para & 3 & 20 & 15 \\
\hline Por & 6 & 5 & 126 \\
\hline
\end{tabular}

Por otro lado, la oposición entre contextos prepositivos (24\%) y no prepositivos (21\%) no arroja diferencias significativas en la selección de allí, por lo que no podemos descartar el azar en su configuración. Con todo, es justo resaltar que la dirección de esas proporciones es idéntica a la observadas por Company/Espinosa (2014) en diversos momentos de la historia del español.

No ocurre así con el modo de acción de los verbos, cuyos cuatro grupos arrojan cifras de uso de alli muy similares, y en todo caso, diferentes a las planteadas previamente. De este modo, no encontramos una mayor asociación de los adverbios en -í con los verbos de estado (20\%), ni un mayor rechazo entre los verbos de movimiento (22\%). Por último, ni los verbos de lengua (23\%), ni los verbos de acción (28\%) muestran un comportamiento singular que haga pensar en la relevancia de este factor para explicar la variación adverbial.

Lo mismo sucede, finalmente, con los otros tres factores sintácticos considerados (adyacencia, función del adverbio y combinatoria). El único que ofrece algunas diferencias frecuenciales de cierta envergadura es el relativo a la función del adverbio. De este modo, en la tabla 5 podemos ver cómo los complementos del verbo (22\%) seleccionan alli en mayor medida que los complementos de otras categorías (sustantivos, pronombres, adverbios) (15\%), aunque estas diferencias no están avaladas por el programa de regresión, un hecho al que podría no ser ajena la extraordinaria irregularidad muestral entre ambos grupos.

Del mismo tenor son los resultados en el plano extralingüístico. Las aparentes diferencias generolectales (hombres: 23\%; mujeres: 16\%) aparecen lastradas por insuficiencias en la representación de las muestras femeninas en el corpus, lo que nos impide ir más lejos en la interpretación de los datos. Igual ocurre, aunque esta vez la representación sea mucho más equilibrada, por lo que al estatus social de los escritores se refiere. Aparentemente, hay una mayor inclinación hacia el empleo de allí entre las clases más humildes (24\%) (vs. 18\% entre las demás), pero tampoco en este caso podemos descartar la hipótesis nula en virtud de los datos disponibles. Finalmente, las cartas entre individuos que mantienen diversos tipos 
de relación entre sí (estrecha, intermedia y distante) configuran un factor socioestilístico con nula repercusión en el fenómeno analizado.

Poco alentadores son también los resultados que encontramos a propósito del lugar de origen de los escritores y el contexto en que escribieron sus cartas. Por lo que al primero se refiere, la tabla 6 muestra la distribución de las frecuencias de uso de los adverbios entre aquellos grupos dialectales que han obtenido un número de ocurrencias de la variable igual o superior a veinte.

Tabla 6: Distribución de las ocurrencias de allí y allá por grupos dialectales

\begin{tabular}{llllll}
\hline & \multicolumn{1}{c}{ Allí } & Allá & \\
\hline Procedencia & $\mathbf{N}$ & \% & $\mathbf{N}$ & $\%$ & $\boldsymbol{\Sigma}$ \\
\hline Navarra-País Vasco & 9 & 13 & 57 & 87 & 66 \\
\hline Castilla la Vieja & 49 & 21 & 184 & 79 & 233 \\
\hline Madrid & 63 & 49 & 66 & 51 & 129 \\
\hline Castilla la Nueva & 42 & 16 & 216 & 84 & 258 \\
\hline Extremadura & 42 & 24 & 132 & 76 & 174 \\
\hline Andalucía & 34 & 12 & 149 & 88 & 276
\end{tabular}

Como se puede apreciar, la preferencia por allá es claramente mayoritaria en todos los grupos dialectales, y tan solo la selección de allí se dispara en el grupo de autores madrileños, donde alcanza el 49\% de los usos adverbiales. Sin embargo, un análisis más detenido de los datos revela que en esos resultados tiene mucho que ver la sobrerrepresentación de un hablante, el ya mencionado Celedón Favalis (ver 4.2). Descartado del análisis, las proporciones del grupo madrileño descienden hasta el $24 \%$, cifras ya mucho más cercanas al resto. Por otro lado, el supuesto origen meridional de las formas en -á, que se habría trasplantado a América en las primeras décadas del siglo XVI, para evolucionar a partir de ahí como un americanismo, no se advierte tampoco con los datos disponibles. Ciertamente, la selección entre los autores andaluces de allá en muy notable (88\%), pero desciende entre los extremeños, el segundo grupo de inmigrantes más numeroso que llegó a América en los primeros momentos de la colonización (76\%). Por otro lado, el papel de los andaluces como principales valedores de allá no es único, pues está compartido con el de otras procedencias dialectales muy diversas: vascos (13\%) y castellano-manchegos (16\%). En definitiva, con los datos disponibles no se vislumbran diferencias dialectales que permitan delimitar las principales isoglosas de este fenómeno de variación en el siglo XVI.

Lo mismo sucede, finalmente, con el contexto en que se escribieron los textos, con diferencias mínimas, y en ningún caso significativas, entre quienes escri- 
bieron sus textos en América (22\%), en contextos de intenso contacto interdialectal, y quienes lo hicieron desde España (19\%), en situaciones mucho menos excepcionales. Por otro lado, un análisis del eje cronológico tampoco permite ver diferencias significativas entre ambos grupos en ningún periodo específico del siglo XVI. Aunque las diferencias muestrales vuelven a ser en este punto destacadas, nuestros datos no avalan, pues, la existencia de desenlaces lingüísticos singulares en función esas situaciones de extrema movilidad geográfica y social, como las que se han propuesto en ocasiones (Penny 2000; Tuten 2003; Kerswill 2013). Por el contrario, coinciden con otros fenómenos de variación y cambio lingüístico analizados previamente en el seno del presente proyecto de sociolingüística histórica, y en los que tampoco hemos apreciado diferencias asociadas con este factor. ${ }^{15}$

\section{Conclusiones}

A partir de un corpus epistolar compuesto íntegramente por cartas privadas escritas por casi setecientos españoles a lo largo del siglo XVI, en las páginas anteriores hemos tenido ocasión de comprobar varios resultados. En primer lugar, que los adverbios demostrativos que sirven para la expresión de coordenadas espacio-temporales lejanas, allí y allá, pueden conceptualizarse perfectamente como variantes de una misma variable lingüística, ya que ambas comparten unas mismas restricciones estructurales y socioestilísticas. Ello significa que tanto allí como allá aparecen en todos y cada uno de los contextos analizados, aunque, eso sí, en diferentes proporciones.

Una segunda conclusión, esta vez más inesperada, es que, al menos en el corpus del siglo XVI estudiado, allá es la forma no marcada y destacadamente más frecuente en el habla. En este sentido, nuestros datos no coinciden con los observados en recuentos previos en los que el adverbio allí se revela como la estrella indiscutible en el firmamento de los adverbios demostrativos, con cifras que superan ampliamente a las del resto en todas las etapas de la historia del español. Aunque en el corpus epistolar analizado para la ocasión se aprecian tendencias de cambio favorables a allí, especialmente en las últimas décadas de la centuria,

15 Así ocurre, por ejemplo, con fenómenos como la alternancia en las oraciones de relativo locativas entre nexos adverbiales (la casa donde...) y pronominales (la casa en (la) que...), en varios momentos de la historia (Blas Arroyo/Velando, 2017), la ausencia del nexo que en las subordinadas sustantivas dependientes de un verbo doxástico en el periodo clásico (creo (que) no lo hará) (Blas Arroyo/Porcar 2016) o la expansión del relativo quienes con antecedentes plurales en ese mismo periodo (Blas Arroyo/Velando 2019). 
los usos de este adverbio se ven en todo momento superados por los de su variante competidora.

A nuestro juicio, la razón de estos resultados divergentes cabe encontrarla en la tipología textual manejada en cada caso. Si en los textos literarios, cronísticos o jurídico-administrativos empleados más habitualmente en la lingüística diacrónica predominan los usos fóricos de los adverbios, y son mucho menos habituales los deícticos, en los intercambios epistolares estos se hallan mucho más equilibrados. Aunque, lógicamente, no faltan ocurrencias de los primeros, como en el relato de historias de los autores a sus destinatarios, las cartas privadas tienen también numerosas concomitancias con el diálogo. Así, el remitente localiza a menudo el momento de la enunciación con adverbios de cercanía (aquí, acá), y lo mismo hace con las coordenadas espacio-temporales que rodean al destinatario, a través de los adverbios de lejanía. Nuestra hipótesis es, pues, que las características del texto epistolar, más cercanas a la inmediatez comunicativa y, por tanto, al habla oral, justifican unos usos significativamente diferentes a los encontrados en otras tradiciones discursivas, al menos en el periodo analizado en estas páginas.

Un tercer resultado con implicaciones teóricas relevantes es la constatación de que, en términos absolutos, ninguno de los factores esgrimidos en la bibliografía para la selección de los adverbios se ve avalado por el análisis empírico. Por ejemplo, las pretensiones de que las formas en -í son portadoras de significados precisos, estáticos y absolutos, mientras que las formas en -á lo son de sentidos vagos, dinámicos y contrastivos, no resisten el análisis de los datos, ya que en todos y cada uno de esos contextos -y de otros del mismo tenor- el adverbio allá aventaja con claridad a su adversario.

Distinto es el caso cuando el contraste se establece a partir de la influencia del contexto variable en la selección de una forma determinada. En efecto, a la luz de los datos disponibles no se podría afirmar que allí es el adverbio utilizado en la lengua para la expresión de contenidos espacio-temporales precisos, ya que en el corpus epistolar hay todavía más ejemplos de localizaciones precisas con allá (56\%) -el supuesto adverbio de la imprecisión-. Lo que sí se puede sostener con toda rotundidad es que la precisión es un factor determinante en la selección de allí, a mucha distancia de los contextos imprecisos, que desfavorecen enormemente la elección del adverbio, al menos en el corpus del XVI. Lo mismo ocurre con la expresión de la locación estática: hay muchos más casos de estatividad con allá (76\%) que con alli (24\%), lo cual no empece que la expresión de los estados sea uno de los contextos que más alientan la selección del adverbio. En ese sentido, pues, y solo en ese sentido, podemos confirmar la asociación de los adverbios con lo pretendido en la bibliografía. De este modo, y conforme a lo previsto, las formas de allí aparecen alentadas no solo en las coordenadas precisas y estativas, sino también 
en los usos no contrastivos, así como en aquellos en los que aparecen otras formas en -í en el contexto previo, y en los contextos de anteposición al verbo.

Por el contrario, otras restricciones planteadas en el pasado no se ven confirmadas con los datos actuales, ni siquiera en los términos que apuntábamos en el párrafo anterior. Así ocurre con algunos factores estructurales, como el contraste entre entornos prepositivos o no prepositivos, o el modo de acción de los verbos en cuyos predicados participa el adverbio. Pero también con los de carácter socioestilístico. Ninguno de ellos revela la suficiente fuerza como para condicionar de manera significativa los usos adverbiales, incluida la procedencia geográfica de los escritores o el contexto en que se escribieron las cartas, lo que deja sin confirmar el supuesto americanismo de las formas en -á.

Qué puede ocurrir con estos condicionantes y con la distribución de las formas adverbiales en etapas más avanzadas de la historia del español es una pregunta que se nos antoja apasionante, pero cuya respuesta tenemos que dejar, de forma obligada, para una ocasión futura.

\section{Bibliografía}

\subsection{Corpus}

Cartas de particulares en Indias del siglo XVI = Fernández Alcaide, Marta, Cartas de particulares en Indias del siglo XVI. Edición y estudio discursivo, Frankfurt, Vervuert, 2009.

Desde la otra orilla = Martínez Martínez, María del Carmen (ed.), Desde la otra orilla. Cartas de Indias en el Archivo de la Real Chancillería de Valladolid, siglos XVI-XVIII, León, Junta de Castilla y León, 2007.

Die private Korrespondenz spanischer Emigranten aus Amerika = Stangl, Werner, Zwischen Authentizität und Fiktion. Die private Korrespondenz spanischer Emigranten aus Amerika, 1492-1824, Wien/Köln/Weimar, Böhlau, 2012.

El hilo que une = Sánchez Rubio, Rocío/Testón Núñez, Isabel, El hilo que une. Las relaciones epistolares en el Viejo y el Nuevo Mundo, siglos XVI-XVIII. Mérida, Universidad de Extremadura, 1999.

\subsection{Referencias}

Alvar, Manuel/Pottier, Bernard, Morfología histórica del español, Madrid, Gredos, 1983. Bello, Andrés, Gramática, Caracas, Ministerio de Educación, 1972 [11847].

Bergs, Alexander, Social Networks and Historical Sociolinguistics. Studies in Morphosyntactic Variation in the Paston Letters (1427-1503), Berlin, Mouton de Gruyter, 2005.

Bergs, Alexander, The uniformitarian principle and the risk of anachronisms in language and social history, in: Hernández-Campoy, Juan A./Conde-Silvestre, Juan C. (edd.), 
The Handbook of Historical Sociolinguistics, Malden (Mass.), Wiley-Blackwell, 2012, $80-98$.

Biber, Douglas, Dimensions of register variation. A cross-linguistic comparison, Cambridge, Cambridge University Press, 1995.

Blas Arroyo, José Luis/González-Martínez, Juan, La alternancia «deber/deber de» + infinitivo en el siglo XVI: factores condicionantes en un fenómeno de variación sintáctica a partir de un corpus epistolar, Spanish in Context 11 (2014), 76-96.

Blas Arroyo, José Luis/Porcar, Margarita, Un marcador sociolingüístico en la sintaxis del siglo de Oro. Patrones de variación y cambio lingüístico en completivas dependientes de predicados doxásticos, Revista Internacional de Lingüística Iberoamericana 28 (2016), 157-185.

Blas Arroyo, José Luis/Velando, Mónica, Sobre puntos de la gramática particularmente resistentes al cambio: cuatro (largos) siglos en la evolución de las relativas oblicuas de lugar. Un análisis variacionista, Borealis. International Journal of Hispanic Linguistics 6:1 (2017), 139-174, DOI: 〈http://dx.doi.org/10.7557/1.6.1.4084>.

Blas Arroyo, José Luis/Velando, Mónica, Fases y condicionantes en un cambio gramatical abrupto. Origen y expansión del relativo quienes en el español medio (1500-1740), Revue de Linguistique Romane (2019), en prensa.

Blas Arroyo, José Luis/Porcar, Margarita/Vellón, Javier, Un hito clave en la evolución de las perífrasis modales de infinitivo: análisis sociolingüistico de la alternancia «haber de/tener que» + infinitivo en textos de inmediatez comunicativa del siglo XIX, Revista de Historia de la Lengua Española 8 (2013), 29-62.

Cano, Rafael, Lenguaje espontáneo y retórica epistolar en cartas de emigrantes españoles a Indias, in: Kotschi, Thomas/Oesterreicher, Wulf/Zimmermann, Klaus (edd.), El español hablado y la cultura oral en España e Hispanoamerica, Madrid, Iberoamericana, 1996, 375-404.

Cano, Rafael, Historia de la lengua oral en la Romania: español, in: Ernst, Gerhard/Gleßgen, Martin-Dietrich/Schmitt, Christian/Schweickard, Wolfgang (edd.), Romanische Sprachgeschichte. Ein internationales Handbuch zur Geschichte der Romanischen Sprachen, Berlin/ New York, De Gruyter, 2008, 2439-2446.

Carbonero Cano, Pedro, Deixis espacial y temporal en el sistema lingüístico, Sevilla, Publicaciones de la Universidad de Sevilla, 1979.

Company, Concepción, Historical morphosyntax and grammaticalization, in: Hualde, Ignacio/ Olarrea, Antxon/Rourke, Erin (edd.), Handbook of Hispanic Linguistics, London/New York, Blackwell, 2012, 673-693.

Company, Concepción/Espinosa, Rosa, Adverbios demostrativos de lugar, in: Company, Concepción (ed.), Sintaxis histórica de la lengua española. Tercera parte: Adverbios, preposiciones y conjunciones. Relaciones interoracionales, México, Fondo de Cultura Económica y Universidad Nacional Autónoma de México, 2014, 129-246.

DCECH = Corominas, Juan, Diccionario crítico etimológico castellano e hispánico (con la colaboración de José Antonio Pascual), 6 vol., Madrid, Gredos, 1980-1991.

Cuervo, Rufino José, Diccionario de construcción y régimen de la lengua castellana, continuado y editado por el Instituto Caro y Cuervo, Bogotá, Instituto Caro y Cuervo, 1953.

Dossena, Marina/Tieken-Boon van Ostade, Ingrid, Studies in Late Modern English Correspondence. Methodology and Data, Bern, Lang, 2008.

Elspaß, Stephan, The use of private letters and diaries in sociolinguistic investigation, in: Hernández-Campoy, Juan A./Conde-Silvestre, Juan C. (edd.), The Handbook of Historical Sociolinguistics, Malden (Mass.), Wiley-Blackwell, 2012, 156-169. 
Fernández Alcaide, Marta, Cartas de particulares en Indias del siglo XVI. Edición y estudio discursivo, Frankfurt, Vervuert, 2009 (con CD-ROM).

Gallucci, María José, Variación entre los adverbios demostrativos aquí-acá en el habla de Mérida, Lingua Americana 20 (2007), 54-66.

García Mouton, Pilar, Tratamientos en las cartas de Indias, in: Forastieri, Eduardo/Cardona, Julia/López Morales, Humberto/Morales, Amparo (edd.), Estudios de lingüística hispánica. Homenaje a María Vaquero, San Juan (Puerto Rico), Editorial de la Universidad de Puerto Rico, 1999, 263-276.

García y Colomé Góngora, Samari P., Adverbios demostrativos de lugar. Estructura y diacronía, Tesis de maestría inédita, México, Universidad Nacional Autónoma de México, 2012.

Hebda, Anna, Phonological variables, in: Hernández-Campoy, Juan A./Conde-Silvestre, Juan C. (edd.), The Handbook of Historical Sociolinguistics, Malden (MA), Wiley-Blackwell, 2012, 237-251.

Hernández-Campoy, Juan Manuel/Schilling, Natalie, The application of the quantitative paradigm to historical sociolinguistics. Problems with the generalizability principle, in: Hernández-Campoy, Juan A./Conde-Silvestre, Juan C. (edd.), The Handbook of Historical Sociolinguistics, Malden (Mass.), Wiley-Blackwell, 2012, 63-79.

Jakobson, Roman, Linguistics and poetics, in: Sebeok, Thomas A. (ed.), Style in language, Cambridge (Mass.), MIT Press, 1960, 350-377.

Johnson, Daniel E., Getting off the GoldVarb standard. Introducing Rbrul for mixed effects variable rule analysis, Language and Linguistic Compass 3:1 (2009), 358-383, <https://doi.org/ 10.1111/j.1749-818X.2008.00108.x> [ultimo acceso: 07.03.2019].

Kabatek, Johannes, Sintaxis histórica del español y cambio lingüístico. Nuevas perspectivas desde las tradiciones discursivas, Frankfurt/Madrid, Vervuert/Iberoamericana, 2008.

Kany, Charles, Sintaxis hispanoamericana, Madrid, Gredos, 1945-1969.

Kerswill, Paul, Identity, ethnicity and place: the construction of youth language in London, in: Auer, Peter/Hilbert, Martin/Stukenbrock, Anja/Szmrecsanyi, Benedikt (edd.), Space in Language and Linguistics, London, De Gruyter, 2013, 128-164.

Koch, Peter/Oesterreicher, Wulf, La lengua hablada en la Romania: español, francés, italiano, Madrid, Gredos, 2007 [ $\left.{ }^{1} 1990\right]$.

Labov, William, Principles of Linguistic Change. Internal Factors, Philadelphia, Blackwell, 1994. Lavandera, Beatriz, Variación y significado, Buenos Aires, Hachette, 1984.

López de la Huerta, Joseph, Examen de la posibilidad de fixar la significación de los sinónimos de la lengua castellana, Madrid, Imprenta Real, 1799.

López Serena, Araceli, Oralidad y escrituralidad en la recreación literaria del español coloquial, Madrid, Gredos, 2007.

Nevala, Minna, Friends will be «friends»? The sociopragmatics of referential terms in early English letters, in: Jucker, Andreas/Schreier, Daniel/Hundt, Marianne (edd.), Corpora. Pragmatics and Discourse, Amsterdam/New York, Rodopi, 2009, 83-103.

Nevalainen, Tertu/Raumolin-Brnnberg, Helena, Historical Sociolinguistics. Language Change in Tudor and Stuart England, London, Longman Pearson Education, 2003.

Oesterreicher, Wulf, Textos entre inmediatez y distancia comunicativas. El problema de lo hablado escrito en el Siglo de Oro, in: Cano Aguilar, Rafael (ed.), Historia de la lengua española, Barcelona, Ariel, 2004, 729-769.

Okulska, Urszula, Performing the world of politics through the discourse of institutional correspondence in Late Middle and Early Modern England, in: ead./Cap, Piort (edd.), Perspectives in politics and discourse, Amsterdam, Benjamins, 2010, 173-197. 
Otte, Enrique, Cartas privadas de emigrantes a Indias, 1540-1616, Sevilla, Consejería de Cultura Junta de Andalucía/Escuela de Estudios Hispano Americanos de Sevilla, 1988.

Palander-Collin, Minna/Nevala, Minna, Letters and letter writing. Introduction, European Journal of English Studies 9:1 (2005), 1-7.

Penny, Ralph, Variation and Change in Spanish, Cambridge, Cambridge University Press, 2000.

Pereira-Scherre, Maria/Naro, Anthony J., The serial effect on internal and external variables, Language Variation and Change 4 (1992) 1-13.

Pérez Saldanya, Manuel/Rigau Oliver, Gemma, «Totz hic viuen, ací, e yo sol no yc puc viure!»: una aproximació histórica als adverbis demostratius, in: Lloret, Maria-Rosa/Pons, Clàudia (edd.), Noves aproximacions a la fonologia i a la morfología del català, Alacant, Institut Interuniversitari de Filologia Valenciana, 2011, 459-488.

Pickering, Martin J./Ferreira, Victor S., Structural priming. A critical review, Psychological Bulletin 134 (2008), 427-459.

Poplack, Shana/Malvar, Elisabete, Elucidating the transition period in linguistic change. The expression of the future in Brazilian Portuguese, Probus 19 (2007), 121-169.

RAE 1931 = Real Academia Española, Gramática de la lengua española, Madrid, Espasa, 1931.

RAE/ASALE 2009 = Real Academia Española/Asociación de las Academias de la Lengua Española, Nueva gramática de la lengua española, Madrid, Espasa Libros, 2009.

Raumolin-Brunberg, Helena, Language change in adulthood. Historical letters as evidence, European Journal of English Studies 9:1 (2005), 37-51, <https://doi.org/10.1080/1382557050 0068125> [último acceso: 10.12.2018].

Real Academia Española, Diccionario de la lengua española, Madrid, Espasa-Calpe, ${ }^{21} 1992$.

Rodríguez, Jilma, Uso de los deícticos espaciales en el habla de Caracas, Tesis de maestría, Universidad del Zulia, 1994.

Sacks, Norman P., An analysis of Hispanic adverbs of place beyond the rest/motion distinction. Sound symbolism, relativity of focus, and correspondences to English «there», in: Morgan, Terrell A./Lee, James F./VanPatten, Bill (edd.), Languages and Language Use. Studies in Spanish, Lanham (MD), University Press of Ann Arbor, 1987, 289-315.

Sánchez Lancis, Carlos, Estudio de los adverbios de espacio y tiempo en el español medieval, 3 vol., tesis doctoral, Barcelona, Universidad Autónoma de Barcelona, 1990.

Schneider, Edgar W., Investigating historical variation and change in written documents, in: Chambers, Jack/Schilling, Natalie (edd.), The Handbook of Language Variation and Change, London, Wiley-Blackwell, 2013, 57-81, <https://doi:10.1002/9781118335598.ch3> [último acceso: 10.12.2018].

Seco, Manuel, Diccionario de dudas de la lengua española, Madrid, Aguilar, ${ }^{5} 1967$.

Sedano, Mercedes, Los adverbios demostrativos en el español de Caracas y de otras ciudades hispanohablantes, Madrid, UNED, 1996.

Sedano, Mercedes, Los adverbios demostrativos en diez ciudades hispanohablantes: resultados de una encuesta, in: Carbonero, Pedro/Casado Velarde, Manuel/Gómez Manzano, Pilar (edd.), Lengua y discurso. Estudios dedicados al profesor Vidal Lamíquiz, Madrid, Arco Libros, 2000, 917-934.

Tagliamonte, Sali A., Variationist Sociolinguistics. Change, Observation, Interpretation, Oxford, Wiley-Blackwell, 2012.

Terrado Pablo, Xavier, Sobre el valor de la alternancia /í/-/á/ en los adverbios de lugar del español, Sintagma 2 (1990), 45-54 (= 1990a).

Terrado Pablo, Xavier, Sobre la forma de contenido de los adverbios de lugar. Cuestiones de diacronía, Sintagma 2 (1990), 55-66 (= 1990b). 
Travis, Catherine. E., Genre effects on subject expression in Spanish. Priming in narrative and conversation, Language Variation and Change 19 (2007), 101-135.

Tuten, Donald, Koineization in Medieval Spanish, Berlin, De Gruyter, 2003.

Villegas, Alberto, Le parler venezuelien de la región de Trujillo, Tesis doctoral, Bordeaux, Université de Bordeaux III, 1990. 